\title{
Evidence that type I diabetes and thyrogastric autoimmunity have different genetic determinants
}

\author{
A N GORSUCH, B M DEAN, G F BOTTAZZO, J LISTER, A G CUDWORTH
}

\section{Summary and conclusions}

The prevalences of autoimmune endocrine disease and relevant organ-specific autoantibodies were determined in 141 patients with type I (insulin-dependent) diabetes and their families. All available members of the families were genotyped for HLA. Islet-cell antibody was found in $10(4 \%)$ out of 248 unaffected siblings, all of whom were genetically potential cases of diabetes. One developed classical symptoms six months later. In contrast, thyroid and gastric parietal-cell antibodies occurred independent of the HLA-linked susceptibility to diabetes.

These results suggest that different genes control the production of these autoantibodies and the susceptibility to type I diabetes.

\section{Introduction}

Both hereditary and environmental factors are concerned in the aetiology of type I (insulin-dependent) diabetes mellitus (DM). Probably the major genetic susceptibility to DM is determined by a gene in the HLA regions of chromosomes 6. In Caucasians this gene (which we term $S_{1}$ ) is in linkage disequilibrium with the HLA haplotype DW3-DRW3-B8-A1. A different gene $\left(S_{2}\right)$, in linkage disequilibrium with DR4,DRW4, $\mathrm{B} 15, \mathrm{CW} 3$, and $\mathrm{A} 2$, possibly increases the risk of DM when present with $\mathrm{S}_{1} .^{2}{ }^{3}$ Family studies (as opposed to population studies) show a close linkage between these genes and the HLA regions of chromosomes 6 (the HLA haplotypes) transmitted in each family whether or not these haplotypes include the specificities mentioned. ${ }^{4}$ Thus defining HLA phenotypes in all members of a diabetic's family, and hence deducing the HLA genotypes, permits haplotype-segregation analysis to determine which of the unaffected siblings may be susceptible to DM.

Several diseases, particularly the autoimmune endocrinopathies, are associated with HLA-B8, ${ }^{5}{ }^{6}$ and there is an increased prevalence both of these diseases and of organ-specific humoral autoimmunity in type I diabetics and their relatives. ${ }^{7}{ }^{8}$ The detection of pancreatic islet-cell antibody (ICA) in diabetes ${ }^{9}$ apparently supported the classification of type I DM as an autoimmune endocrinopathy, but this may be an oversimplification. Thus in contrast to other organ-specific autoantibodies ICA is transient in most diabetics, being almost invariably detectable at diagnosis but persisting beyond two to three years in only $15-20 \%$ of cases. ${ }^{10}$ In polyendocrine disease, however, ICA generally persists for many years, and the few patients with type I DM alone who have persistent ICA

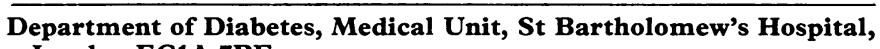
London EC1A 7BE

A N GORSUCH, MRCP, honorary lecturer in medicine

B $M$ DEAN, PHD, lecturer

A G CUDWORTH, MD, FRCP, consultant physician and senior lecturer

The Middlesex Hospital, London W1N 8AA

G F BOTTAZZO, MD, lecturer in immunology

King Edward VII Hospital, Windsor

J LISTER, MD, FRCP, consultant physician
}

apparently form a distinct, homogeneous subgroup of diabetics characterised by a comparatively late onset of disease, a preponderance of female patients, increased prevalence of organspecific autoimmunity, and a strong family history of autoimmune endocrinopathy. ${ }^{11}$ This subgroup may represent patients with primary autoimmune or type IB DM, whereas juvenile-onset or type IA diabetes (for which transient ICA is a marker) may have a different aetiology, possibly viral.

We must discover whether susceptibility to thyroid and other organ-specific autoimmunity is determined by the same gene as susceptibility to type I DM. Bottazzo et al ${ }^{12}$ tried to resolve this by analysing HLA phenotypes in a group of patients with coexistent type I DM and autoimmune thyroid disease. Their findings-namely, that the relative risk in respect of B8 was roughly additive compared with that in type I DM and Graves's disease when analysed separately-suggested that different HLA-linked genes were responsible for the two diseases. A more powerful method of investigation is by HLA-haplotypesegregation analysis. If the B8-linked "diabetogenic" and "thyroid-autoimmunity" genes were identical, then autoimmunity would be expected to occur preferentially in subjects with a diabetogenic haplotype. We present strong evidence to the contrary.

\section{Subjects and methods}

Population studied-The Barts-Windsor Prospective Family Study was begun in 1978 to investigate genetic, immunological, and environmental factors in the aetiology of type I DM. The 158 Caucasian families who participated were selected at random with respect to autoimmune endocrinopathy, but each contained a classical type I diabetic proband with at least one available sibling aged under 20. HLA haplotypes were unequivocally distinguished in 141 families, the others being excluded from the present analysis because of expaternity of the proband (six families) or HLA-A, B, C homozygosity in a parent. Half-siblings were also excluded. Our analysis was therefore conducted on 141 diabetic probands (mean age 14.0 years, range 4-29; male:female ratio $1 \cdot 2: 1$; mean duration of diabetes 5.6 years), 255 siblings (mean age 14.2 years, range 1-32), 136 fathers, and 140 mothers (mean ages 43.4 and 40.3 years respectively).

HLA genotypes-HLA-A, B, and C typing was performed on all available members of the families by the microlymphocytotoxicity technique with 100 fully standardised antisera covering all known specificities in Caucasian populations. ${ }^{13}$

Autoantibodies-ICA and gastric parietal-cell antibody were sought by the standard immunofluorescence sandwich technique using undiluted sera on fresh blood-group-O pancreas obtained at necropsy and group-O stomach obtained at partial gastrectomy respectively. ${ }^{9}$ Weakly positive reactions were confirmed on at least two different substrates. Thyroglobulin and thyroid microsomal antibody titres were estimated with commercial haemagglutination kits (Wellcome Reagents Ltd) of formolised red blood cells coated with the appropriate human antigens. We took titres of at least $1 / 20$ and $1 / 400$ respectively as positive.

Statistical significance was assessed by the $\chi^{2}$ test with Yates's correction.

\section{Results}

\section{CLINICAL AUTOIMMUNE DISEASE}

Type I DM was present in seven siblings, seven fathers, and two mothers. There was no excess of type II DM $(0.7 \%$ of first-degree relatives). Autoimmune thyroid disease was reported in first-degree 
or second-degree relatives of 37 probands $(26 \%)$; they included 15 mothers and three fathers $(11 \%$ and $2 \%$ respectively; $\mathrm{p}<0.01)$ Most had a history of thyrotoxicosis, but three mothers had primary myxoedema and two euthyroid goitres. Other organ-specific autoimmune diseases were less common, including pernicious anaemia (three families), vitiligo (five), and coeliac disease (three). Nineteen probands $(13 \%)$ had first- or second-degree relatives with a history of rheumatoid arthritis, which is the first time that such an association has been noted. Fifty-seven families $(40 \%)$ reported one or more of these conditions, excluding diabetes, in first- or seconddegree relatives.

\section{ORGAN-SPECIFIC AUTOANTIBODIES IN NON-DIABETIC RELATIVES}

ICA was found in five fathers and three mothers (a prevalence in parents of $3 \%$ ) and in 10 siblings $(4 \%)$. Interestingly, all the non-diabetic siblings with ICA were potentially susceptible to diabetes, since they had at least one HLA haplotype in common with their probands (table I). Thyroid or gastric parietal-cell antibody (TGA) was present in 56 mothers and 26 fathers $(41 \%$ and $20 \%$ respectively; $\mathrm{p}<0.001)$ and in 29 siblings ( $12 \%$; female excess not significant). In contrast to the distribution of ICA, the distribution of TGA among the non-diabetic siblings (table I) was independent of the degree of HLA identity with the proband. There were no significant differences between these groups in age or sex distribution. The same pattern was observed when thyroid and gastric parietal-cell antibodies were analysed separately. in common with the proband, abruptly developed symptoms of diabetes several months after ICA was detected and after a period of asymptomatic, persistent postprandial hyperglycaemia.

If thyrogastric autoimmunity were determined by the same $S_{1}$ gene as type I DM, then non-diabetic siblings who had both haplotypes in common with their probands would have been expected to show a greater prevalence of TGA than those with neither of them. That this was not so (table I) provides evidence for different genes determining the susceptibilities to type I $D M$ and to other autoimmune endocrinopathies. Though relatively few siblings with TGA are shown in each group in table I, this hypothesis was supported by the results of analysing autoantibodies in relation to HLA-B8-haplotype segregation (table II). By considering only those first-degree relatives with a single B8-positive haplotype we could incorporate the data on parents as well as siblings, which showed no direct association between the occurrence of TGA and the likely presence of an $S_{1}$ diabetogenic gene (table II). Alternatively, genes outside the HLA region may control the production of organ-specific autoantibodies.

A history suggesting rheumatoid arthritis in first-degree or second-degree relatives was obtained in $13 \%$ of families. Although the diagnosis could not always be proved, this finding is interesting because of increasing evidence for a positive association between rheumatoid arthritis and HLA-DRW4,15 which is also a susceptibility factor in type I diabetes.

TABLE I-Prevalence of autoantibodies in non-diabetic siblings of probands

\begin{tabular}{|c|c|c|c|c|c|c|c|c|c|}
\hline \multirow[b]{3}{*}{ No (\%) of siblings with ICA } & \multirow[b]{3}{*}{$\begin{array}{l}\mathrm{M} \\
\mathrm{F}\end{array}$} & & & \multicolumn{4}{|c|}{ HLA haplotypes in common with proband } & \multirow{2}{*}{\multicolumn{2}{|c|}{ Total }} \\
\hline & & \multicolumn{2}{|r|}{ Both } & \multicolumn{2}{|r|}{ One } & \multicolumn{2}{|c|}{ Neither } & & \\
\hline & & $\begin{array}{l}1(5) \\
3(13)\end{array}$ & \} $4(9)$ & $\begin{array}{ll}4 & (5) \\
2 & (4)\end{array}$ & $6(4)$ & $\begin{array}{l}0 \\
0\end{array}$ & \} 0 & $\begin{array}{ll}5 & (4) \\
5 & (4)\end{array}$ & \} 10 \\
\hline No (\%) of siblings with TGA & $\stackrel{\mathrm{M}}{\mathrm{F}}$ & $\begin{array}{l}2(10) \\
5(21)\end{array}$ & \} $7(16)$ & $\begin{array}{l}5 \text { (6) } \\
7(13)\end{array}$ & \} 12 (9) & $\begin{array}{l}4(13) \\
6(17)\end{array}$ & \} $10(15)$ & $\begin{array}{l}11(8) \\
18(16)\end{array}$ & \} $29(12)$ \\
\hline No examined & $\stackrel{M}{\mathrm{~F}}$ & $\begin{array}{l}21 \\
24\end{array}$ & \} 45 & $\begin{array}{l}82 \\
54\end{array}$ & \} 136 & $\begin{array}{l}32 \\
35\end{array}$ & \} 67 & $\begin{array}{l}135(54) \\
113(46)\end{array}$ & 248 \\
\hline
\end{tabular}

ICA $=$ Islet-cell antibody

TGA $=$ Thyroid (microsomal or thyroglobulin) or gastric parietal-cell antibody.

Table II shows the prevalence of autoantibodies in non-diabetic parents and siblings selected for the presence of a single haplotype carrying HLA-B8. In two-thirds of cases the proband also had this haplotype, which was termed the "diabetogenic" B8 haplotype, whereas in the other cases it was termed "non-diabetogenic." The prevalences of TGA in these two groups were almost identical and the age and sex distributions comparable.

TABLE II-Prevalence of autoantibodies in non-diabetic first-degree relatives with one $H L A-B 8$-positive haplotype

\begin{tabular}{llccc}
\hline & & $\begin{array}{c}\text { "Diabetogenic" } \\
\text { HLA-B8 haplotype }\end{array}$ & $\begin{array}{c}\text { "Non-diabetogenic" } \\
\text { HLA-B8 haplotype }\end{array}$ \\
\hline No (\%) with ICA & $\ldots$ & $\ldots$ & $6(6)$ & $2(4)$ \\
No (\%) with TGA & $\ldots$ & $\ldots$ & $26(25)$ & $14(27)$ \\
\hline No examined & & & 105 & 51 \\
\hline
\end{tabular}

ICA = Islet-cell antibody

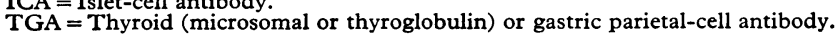

\section{Discussion}

Islet-cell antibody may serve as a predictive marker for insulin-dependent diabetes in older patients initially treated with oral hypoglycaemic agents. ${ }^{14}$ Our results show that ICA may occur in children before the onset of symptomatic insulindependent diabetes. Furthermore, ICA was detected only in those who weregenetically potentially susceptible to DM. Interestingly, one of the siblings with ICA, who had both HLA haplotypes
We have presented strong evidence for genetic heterogeneity within the range of autoimmune endocrinopathies, and our findings reinforce the view that the presence of ICA in the serum of children genetically susceptible to type I DM may be a predictive marker for the disease at a relatively early stage of pathogenesis. This would have important implications should it prove possible to prevent irreversible $\beta$-cell damage in such children.

This study was supported by the Medical Research Council (ANG), the British Diabetic Association, the Juvenile Diabetes Foundation, and the Joint Research Board of St Bartholomew's Hospital. We thank Miss B Watson, Miss V Drummond, Miss J Pritchard, and Dr E Wolf for their accurate typing of HLA, and Miss $M$ Shattock for help with the characterisation of autoantibodies. We also thank Drs W B Thomson, D H Garrow, C H Cheetham, J Scott, and other physicians for allowing us to study their patients.

\section{References}

${ }^{1}$ Cudworth AG. Type I diabetes mellitus. Diabetologia 1978;14:281-91.

2 Cudworth AG, Festenstein H. HLA genetic heterogeneity in diabetes mellitus, Br Med Bull 1978;34:285-9.

${ }^{3}$ Sachs J, Cudworth AG, Jaraquemada D, Gorsuch AN, Festenstein $\mathrm{H}$. Type I diabetes and the HLA-D locus. Diabetologia (in press).

4 Cudworth AG, Woodrow JC. Evidence for HLA-linked genes in "juvenile" diabetes mellitus. $\mathrm{Br}$ Med $\mathcal{F} 1975$;iii :133-5.

5 Nerup J, Cathelineau C, Seignalet J, Thomsen M. In: Dausset J, Svejgaard $\mathrm{A}$, eds. HLA and diseases. Copenhagen:Munksgaard, 1977;149-67.

${ }^{6}$ Cudworth AG. The HLA system, autoimmune endocrinopathy and diabetes mellitus. Eur $\mathcal{F}$ Clin Invest 1978;8:355-7. 
7 Irvine WJ, Clarke BF, Scarth L, Cullen DR, Duncan LJP. Thyroid and gastric autoimmunity in patients with diabetes mellitus. Lancet 1970; ii:163-8.

${ }^{8}$ Bottazzo GF, Mann JI, Thorogood M, Baum JD, Doniach D. Autoimmunity in juvenile diabetics and their families. $\mathrm{Br}$ Med $\mathcal{F} 1978$; ii: $165-8$.

${ }^{9}$ Bottazzo GF, Florin-Christensen A, Doniach D. Islet cell antibodies in diabetes mellitus with autoimmune polyendocrine deficiencies. Lancet 1974 ;ii:1279-82.

${ }^{10}$ Lendrum R, Walker G, Cudworth AG, et al. Islet cell antibodies in diabetes mellitus. Lancet 1976;ii:1273-6.

11 Cudworth AG, Bottazzo GF, Doniach D. Genetic and immunological factors in type I diabetes mellitus. In: Irvine WJ, ed. Immunology of diabetes. Edinburgh:Teviot Scientific Publications (in press).
12 Bottazzo GF, Cudworth AG, Moul DJ, Doniach D, Festenstein H. Evidence for a primary autoimmune type of diabetes mellitus. $\mathrm{Br} \mathrm{Med} \mathcal{F}$ 1978;ii:1253-5.

13 Joysey VC, Wolf E. HLA-A, $-B$ and $-C$ antigens. Their serology and cross reactions. $\mathrm{Br}$ Med Bull 1978;34:217-22.

14 Irvine WJ, Gray RS, McCallum CJ. Pancreatic islet-cell antibody as a marker for asymptomatic and latent diabetes and pre-diabetes. Lancet 1976;ii :1097-1102.

15 Panayi GS, Wooley P, Batchelor JR. Genetic basis of rheumatoid disease: HLA antigens, disease manifestations, and toxic reactions to drugs. Br Med f 1978;ii:1326-8.

(Accepted 17 October 1979)

\title{
Role of non-medical staff in screening for breast cancer
}

\author{
W D GEORGE, R A SELLWOOD, D ASBURY, G HARTLEY
}

\section{Summary and conclusions}

In a feasibility study of mass population screening for breast cancer by clinical examination and mammography the ability of non-medical staff (nurses and radiographers) to act as primary screeners was compared with that of medical staff (surgeons and radiologists). In 240 women with cancer the rate of detection of the disease by the non-medical staff was comparable to that of the medical staff, although the non-medical staff detected more cancers by mammography alone than did the medical staff. The rate of detection by surgeons and particularly nurses was lower in women without symptoms than in those with symptoms, whereas the incidence of detection by radiologists and radiographers was lower in women aged under 50 than in those over 50. The rate of detection by all groups of staff significantly increased with increases in tumour size.

The results suggest that non-medical staff can act effectively as primary screeners, but that for the detection of cancer in asymptomatic women, particularly those over 50, mammography is probably more effective than clinical examination.

\section{Introduction}

The results of a study by the Health Insurance Plan (HIP) of Greater New York suggested that screening for breast cancer leads to early detection and consequently to a significant reduction in mortality. ${ }^{1}$ Hence the Department of Health and Social Security established three centres to determine the feasibility of providing a national screening service. The results from one of these suggested that it would be possible to provide a safe and acceptable service run by trained non-medical staff. ${ }^{2}$

The success of such a service would depend on the ability of non-medical staff to detect cancer in its early stages in asymptomatic women. This ability may be governed by many factors related to the disease, the population screened, and the methods

Department of Surgery, Royal Liverpool Hospital, Liverpool L7 8XP W D GEORGE, MS, FRCS, senior lecturer

University Hospital of South Manchester, Manchester M20 8LR R A SELLWOOD, CHM, FRCS, professor of surgery

D ASBURY, MB, FFR, consultant radiologist

G HARTLEY, MB, FFR, consultant radiologist of screening used. Within the context of a feasibility study it was possible to examine the effect of several factors on the rate of detection of cancer by both medical and non-medical staff and to consider the effect that these factors may have on large-scale screening programmes.

\section{Subjects and methods}

A breast-screening clinic was established in 1973. The methods chosen for screening were clinical examination and mammography. Nurses and radiographers were recruited and given a basic course of instruction in all aspects of breast disease. Additional instruction in clinical examination was given to the nurses and on interpretation of mammograms to the radiographers. The course lasted six weeks.

\section{POPULATION STUDIED}

Invited women-All women over the age of 40 registered with two group practices were invited to attend the clinic for yearly screening.

Referred women-All patients referred to hospital because of symptoms or signs of breast disease were examined in the same clinic and in the same way as the invited women to provide nonmedical staff with a wide experience of abnormalities of the breast in addition to that gained from "well women."

Self-referred women-Many women attended for screening without invitation or referral.

\section{CLINICAL PROCEDURE}

Each patient was interviewed and examined independently by a nurse and a surgeon, who recorded their findings separately on a standard computer document. In the same way each mammogram was read and reported separately by a radiographer and a radiologist.

\section{PERFORMANCE OF MEDICAL AND NON-MEDICAL STAFF}

The performance of medical and non-medical staff was assessed from their ability to detect significant abnormalities in women with cancer. A significant abnormality was defined as one that automatically led to biopsy. ${ }^{3}$ Histological confirmation was obtained in all cases of cancer.

\section{FACTORS AFFECTING PERFORMANCE}

The effect of the following factors on the rate of detection was studied for each group of staff. 